\title{
An Interview with Jill Pipher
}

\author{
Evelyn Lamb
}

Every other year, when a new AMS president takes office, the Notices publishes interviews with the outgoing and incoming presidents. What follows is an edited version of an interview with Jill Pipher, whose two-year term as president ended on January 31, 2021. Pipher is Vice President for Research and Elisha Benjamin Andrews Professor of Mathematics at Brown University. The interview was conducted in December 2020 by freelance writer Evelyn Lamb.

Notices: We're talking in December 2020, at the end of what has been a very challenging year for pretty much everybody. What kinds of challenges has the AMS faced this year, and how have you and the organization responded?

Pipher: Where do I start? First of all, there's the challenge of being able to do our jobs-as mathematicians, as educators, as researchers-in a global pandemic. The thing that was affected most within the organization itself was MathSciNet, which was basically down for a couple of months and then came back. The sheer efforts to go paperless and, at the same time, to support the AMS community with its challenges by providing information and changing meetings to remote meetings, and so forth, were pretty extraordinary. I think we're past the worst of that, thanks to a lot of incredible teamwork and good leadership from the executive director.

Besides the challenges we're all familiar with, there are things that emerged from this and turned out to be really significant: the disproportionate effect of the illness on people of color, the disproportionate effect of the pandemic on research for women in the sciences, who have still borne the brunt of childcare. What that means for the careers of women, and especially women of color, and how that shapes their opportunities down the road, is yet to be seen.

Finally, the overarching social issues, the political and cultural polarization of this country, certainly have been

Evelyn Lamb is a freelance writer in Salt Lake City, UT. Her email address is rootsofuni tyblog@gmai 1 .com.

For permission to reprint this article, please contact: reprint-permission @ams.org.

DOI: https://dx.doi.org/10.1090/noti2248 part of what's happening in our own mathematical community. We don't all have the same understanding of the world, and in certain cases, we find that we aren't even starting from the same premises. Navigating the tension and the misunderstandings and the righteous anger around racial discrimination and Black Lives Matter has been truly challenging. I think the AMS is rising to that challenge in many ways that I'm proud of, and we have a lot of work to do in the future to get where we want to go.

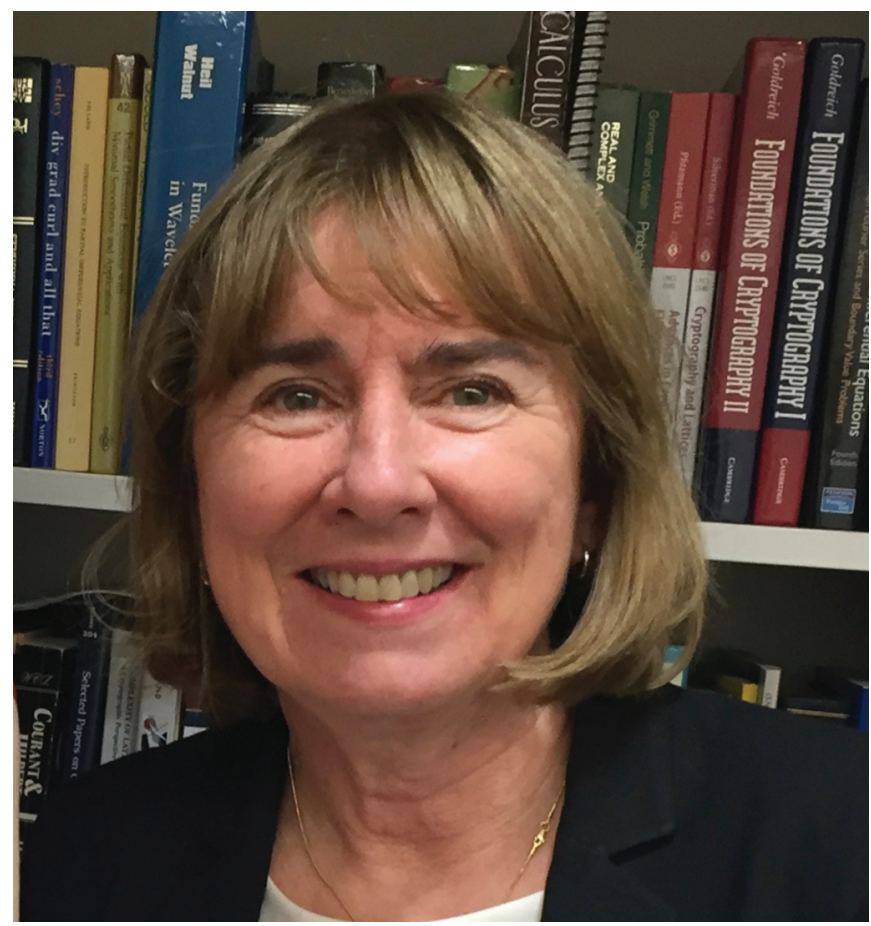

Figure 1. Jill Pipher at Brown University 
Notices: Can you elaborate on that, talk a little bit about the ways that the AMS has been responding to the Black Lives Matter movement this year?

Pipher: One of the things the AMS did on June 10 [joining many other societies and organizations in a show of support for Black Lives Matter] was to close its offices in order to have some day-long meetings of the Executive Council and the Board of Trustees, followed by a Council meeting that evening. A couple of important things emerged. First of all, the Council endorsed the creation of a task force called Understanding and Documenting the Historical Role of the AMS in Racial Discrimination. The co-chairs of that task force, Kasso Okoudjou and Francis Su, started work on filling out the rest of the committee. The committee was charged to produce a report in a very rapid timeframe, and we now have a summary to present and discuss at the next Council meeting in January, with a set of recommendations that will be discussed and digested. Hopefully many of these will be turned into action items for the AMS.

The second thing was the creation of the 2020 Fund. If the Council approves, it will support a fellowship specifically for Black mathematicians and will demonstrate the AMS's commitment to Black mathematicians in this organization. I look forward to discussing the recommendations of the task force in future meetings.

Notices: When we talked in 2018, one of the priorities you mentioned was supporting early-career mathematicians, whether they were going into research and academic careers or not. Do you have any updates on how that has progressed over the past two years?

Pipher: The AMS has continued to invest in its graduate student chapters and recognizes the importance of supporting that work. The Math Research Communities, which bring graduate students and researchers together for an immersive experience in the summer, were only able to be carried out remotely [in 2020], but the financial support has continued and will continue and even expand. It's a tremendously successful program, according to the participants. The graduate students end up working on projects, producing papers, and forming networks and communities that are long-lasting. The Epsilon Fund, which supports math activities for pre-college kids, has been growing over the years and continues to provide funds to support math camps and summer schools.

Notices: Is there a single thing you're most proud of about your tenure as president of the AMS?

Pipher: I would not point to one single thing. I would just say I'm proud that all of this important work continued and that we were able to continue to support the mathematics community in spite of all the organizational, social, public health, and political challenges that we all were facing this year. It was a very difficult year.

Not every initiative that I had ambitiously planned at the beginning of my presidency reached fruition because about halfway through it, the world just fell apart. A lot has been happening at the AMS in spite of that. For one thing, some of our sectional meetings have been held remotely and seem to be going well. The Joint Mathematics Meetings will be very scaled-back, but we will be having major invited addresses, special sessions, and panels. It's very hard to re-create something as wonderful as the JMM remotely, but it will certainly be better than not having anything at all.

Our newest journal was finalized, the Communications of the AMS. I just had the honor and delight of approving its inaugural editorial board, which looks terrific. It has two very dedicated editors-in-chief. This is going to be a donor-funded, open-access journal.

In addition to the work through the task force and Board of Trustees fund to support Black Lives Matter, the AMS Council created a sixth policy committee, the Committee on Equity, Diversity, and Inclusion. The five policy committees that existed were formed in the mid-90s to help create policy to be approved by Council in areas that represented the main mission of the AMS. So the AMS has made it clear that equity, diversity, and inclusion are part of its main mission by creating this sixth policy committee.

In other work, we've been looking at the structure and processes regarding our prizes and formed a new committee, the Prize Oversight Committee, to ensure we have a robust and diverse set of nominations for prizes, that our protocols make it easy to nominate people, and that the prizes are regularly reviewed and continue to meet the standards of the AMS. I think that all in all, there's been a lot going on at the organization.

One of the other things that was really on my mind was advocacy for research, and mathematical research in particular, with general audiences and our representatives in Washington. One of the things I was fortunate to have been asked to take part in was a congressional briefing last year that brought all of my Rhode Island delegates to the room. We had a really great conversation around the importance of government funding and federal funding, in particular for fundamental research that leads to solutions like public-key cryptography.

Notices: How has your role as Vice President for Research at Brown synergized (or not) with being the AMS president?

Pipher: One of the things I get to do as part of the Vice President for Research job is learn about issues in Washington in terms of government policies that affect higher education and universities, so I've learned quite a bit about issues that are important to every aspect of the research 


\section{AMS COMMUNICATION}

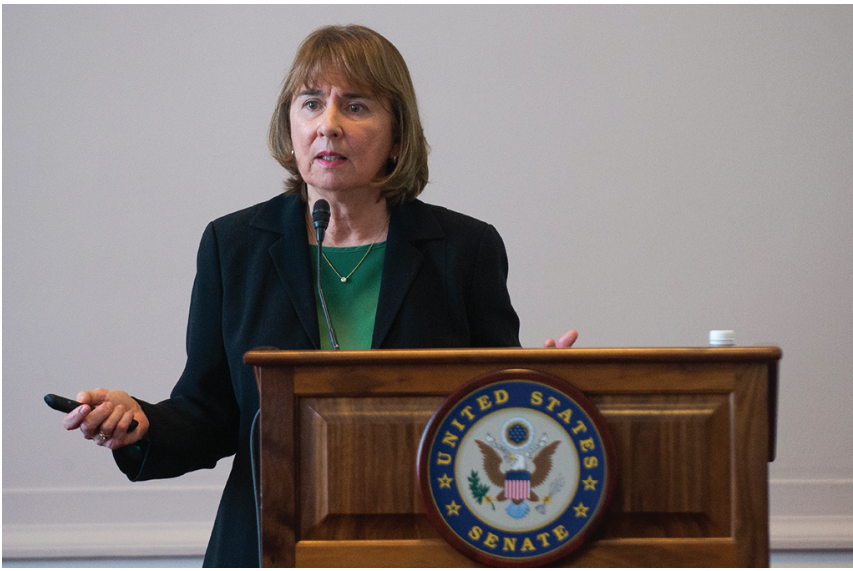

Figure 2. Jill Pipher at a US Senate briefing in Washington, DC

environment. Much of what I learn is relevant even for research that is not carried out in a lab. It affects all of our research. So with that knowledge and discussions that take place, both with my peers at other universities and with our senior administration at Brown, I gain insights into things that I can translate into how to help mathematicians too.

The thing that was most stressful these past eight months was trying to figure out how we were going to reopen research labs safely after the lockdown because we had to get our researchers back to work. That work was incredibly time-consuming and confusing and involved solving a lot of new problems. We approached it very methodically. I chaired a large committee of experts that discussed what to do and how to do it several times a week for many weeks as we were unfolding this process. It wasn't necessarily related to what I do for AMS, but maybe it was sort of synergistic because during this time, I read a number of papers about modeling infectious diseases that I was able to understand pretty quickly because of my background.

Notices: When we talked the last time, you mentioned that time to actually do your own research was at a premium. Is there anything you're excited about being able to work on, or new directions in your own research you want to pursue, after your tenure as president ends?

Pipher: I was on a path where I was able to balance two pretty consuming jobs-my job at the research office at Brown and the AMS - with spending some time each week on a regular basis doing my research. But honestly, after March, that pretty much came to an end. The things that I had to deal with at Brown, shutting down research labs and figuring out how to reopen them again, suddenly doubled my workload. I have been able to keep up with a few things and finished one paper with my collaborator and postdoc. But honestly, if I can just get back into my old research habits, I will be very grateful because it's been the thing that slid away during these last eight or nine months.
Notices: Is there anything else you're excited to get to do as your role as AMS president ends?

Pipher: I've been helping to run a virtual informal learning seminar in analysis here while we're in the pandemic, and I've also started working remotely with a newly-admitted graduate student. So I'm looking forward to taking on some new projects and helping her find some fun things in harmonic analysis to work on.

Notices: What do you think are the biggest challenges facing the AMS in the next few years?

Pipher: One challenge is going to be in meetings and conferences. I think we'll all still want to go to meetings in person; I think we're craving it. At the same time, we're not going to be traveling in the same way that we were. There are going to be changes that are going to be hard to predict in the way we run meetings and conferences. Not being able to predict what those changes look like in people's travel and conference participation is something that an organization like AMS, which has so many activities geared toward travel and meetings, will find challenging.

I think the other challenge is going to be universities and colleges. Institutions of higher education have faced extraordinary budget cuts. They've gone into debt. Some of them will probably close. I think the near-term future of universities and colleges is going to make everything that the AMS and other professional societies have relied on from these institutions challenging, including library subscriptions for books and journals and membership support from the general community. Higher education has been one of the biggest victims of the pandemic, and the consequences have still not played out. We're not really sure how that's going to affect the future of our work, and how that's going to change university education overall.

Creating a truly inclusive and diverse society membership and community is a challenge. I think the AMS recognizes that it's a challenge and is looking for solutions and help from its members. It's a challenge for any institution, any organization, to look at itself and say "this needs to be done better, this needs to be done differently" and to get everybody on board with that.

At the same time, all three of the things I mentioned are opportunities. They are all opportunities to do something different, to do something better, to make the necessary changes in how we serve and support mathematical research. Mathematics is so important to the future of this world that the support of mathematics research is, I think, truly a noble thing. This organization has a huge part to play in that, and that's what makes people dedicated members and makes the staff at AMS dedicated to their job. They know that it's truly a noble cause. 
Notices: What are you most optimistic about with respect to the future of the AMS?

Pipher: I'm most optimistic about the fact that it does seem to me that more and more people in a general audience, in positions in government, in leadership positions, are understanding how central mathematics is to everything. Understanding the importance, the centrality of mathematics, that makes me very optimistic. It means that the organization should be able to continue to thrive.

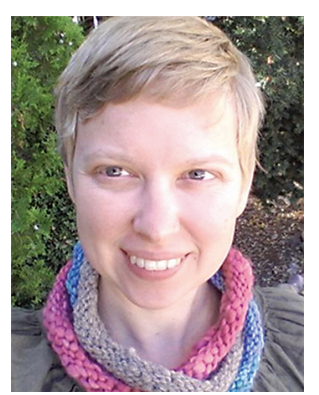

Evelyn Lamb

Credits

Figures 1 and 2 are courtesy of Jill Pipher and Brown University.

Author photo is courtesy of Evelyn Lamb.

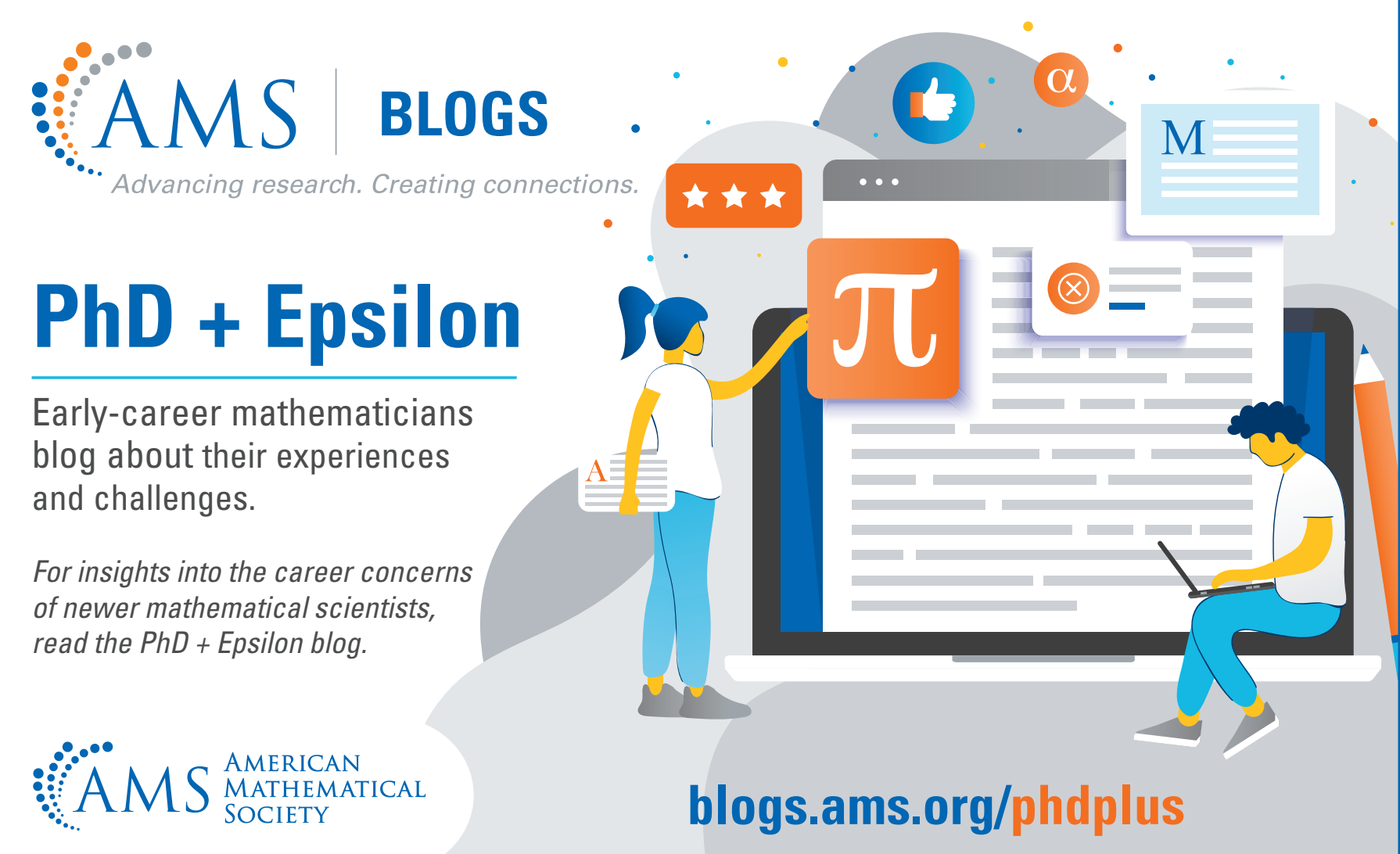

